\title{
KIJK OP JAPAN
}

In de laatste twee decennia van de vorige eeuw is in Japan een aantal overzichtwerken van de Japanse kunst uitgegeven. Vaak zijn het fraai vormgegeven gebonden boeken van fors formaat, voorzien van een doos of een hoes, zoals in Japan gebruikelijk is. Er is veel aandacht besteed aan de afbeeldingen, die vaak groter zijn dan A4-formaat, en ze zijn eerst en vooral een visueel overzicht, per kunstsoort ingedeeld of chronologisch opgezet. Ze kunnen echter ook worden opgevat als een poging tot inventarisatie van het verleden, in de zin dat voor een aantal kunstvormen collecties uit de hele wereld werden nagepluisd en netjes op een rijtje werden gezet. Dit heeft fraaie overzichten opgeleverd van onder andere keramiek, handrolschilderingen, prentkunst en inktschilderkunst, die een goed inzicht geven van wat waar bewaard is gebleven. Steevast worden ook detailopnames van zegels en signaturen gegeven en het zijn dan ook zeer complete werken die voor verzamelaars, handelaren en museummedewerkers belangrijk zijn als naslagwerk.

Eén zo'n serie is Hizo nihon bijutsu taikan ('Overzicht van schatten van Japanse kunst'). ${ }^{1}$ In deze reeks worden de verzamelingen in Europese musea belicht, onder andere het British Museum in Londen (met drie delen), het Musée Guimet in Parijs en het Rijksmuseum voor Volkenkunde in Leiden. In het laatste deel XII komt ook het Rijksmuseum aan bod, met dertien werken. Bij de geselecteerde stukken uit het bezit van het Rijksmuseum zelf ligt de nadruk op werken die van de interactie tussen Nederland en Japan getuigen: Namban-stijl kamerschermen, lakwerk gemaakt naar Nederlandse prenten, of afbeeldingen van Nederlandse schepen. Het bezit van de Vereniging is ook vertegenwoordigd, met vijf voorwerpen. Hieronder volgen $z e$, met de bijbehorende beschrijvingen in vertaling. Het is aardig om te zien waarop nu juist de keuze van de Japanse samenstellers is gevallen, en de beschrijvingen zijn de moeite van het lezen waard. Er werden gerenommeerde auteurs aangezocht, die met hun ervaring en scherpe blik voor verhelderend commentaar zorgden.

De vertaling is hier en daar ter verduidelijking aangevuld met noten. Bij de auteursvermelding komt de familienaam voor de voornaam. 
1. Kwartels en gierst

Tosa Mitsuoki

1654-1681

Hangrolschildering, inkt en kleur op zijde

$27 \times 28 \mathrm{~cm}$

Signatuur: 'Tosa Mitsuoki Sakon Shogen hitsu'

Zegel: 'Mitsuoki no in'

AK-MAK-168

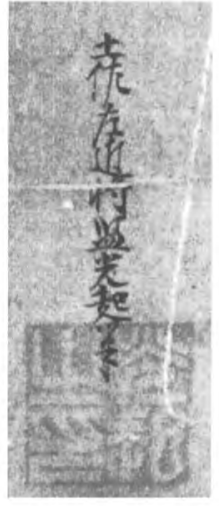

Het zijde van de schildering is harsbruin verkleurd en er zijn ook hier en daar beschadigingen. Dat staat de waardering niet in de weg, want gelukkig is de afbeelding zelf in goede staat bewaard gebleven. Op een herfstveld bewegen zwaar beladen gierst-aren in de wind, staan hibiscus, ballonklokjes en tsuyukusa ${ }^{2}$ in volle bloei en pikt een paartje kwartels naar voedsel.

Het vrouwtje heeft zojuist een sprinkhaan gevangen.

De minutieuze detaillering van het verenkleed is in één woord geweldig. Het is een interessant spel van lijnen, met de zachte welvingen van de gierstbladeren en de spoelvormige kwartels. We krijgen werkelijk inzicht in het superieure vermogen voor compositie en portrettering van Tosa Mitsuoki (1619-1691), terwijl hij dit kleine vlak van nog geen $30 \mathrm{~cm}$ niet eens helemaal heeft gevuld.

Mitsuoki was de grondlegger van de revival van de Tosa-school in de $17 \mathrm{e}$ eeuw. In 1655 werd hij op 38-jarige leeftijd benoemd tot hofschilder en ontving hij de hofrang 'junior vijfde rang, lage graad', ${ }^{3}$ en de titel 'luitenant van de linker-afdeling van de binnen-paleiswacht'. ${ }^{4}$ Vervolgens krijgt hij in 1679 de eretitel hokkyo en in 1685 die van hogen. ${ }^{5}$ Hij maakte illustraties bij klassieke literaire werken als de Genji Monogatari en gedetailleerde afbeeldingen van bloemen en vogels, die hij leerde van de Chinese school van Lian Chu en de zijnen, met afbeeldingen van kwartels als specialiteit. Dit kleine werk uit Amsterdam mag gevierd worden als één van zijn representatieve werken.

Sakakibara Satoru 


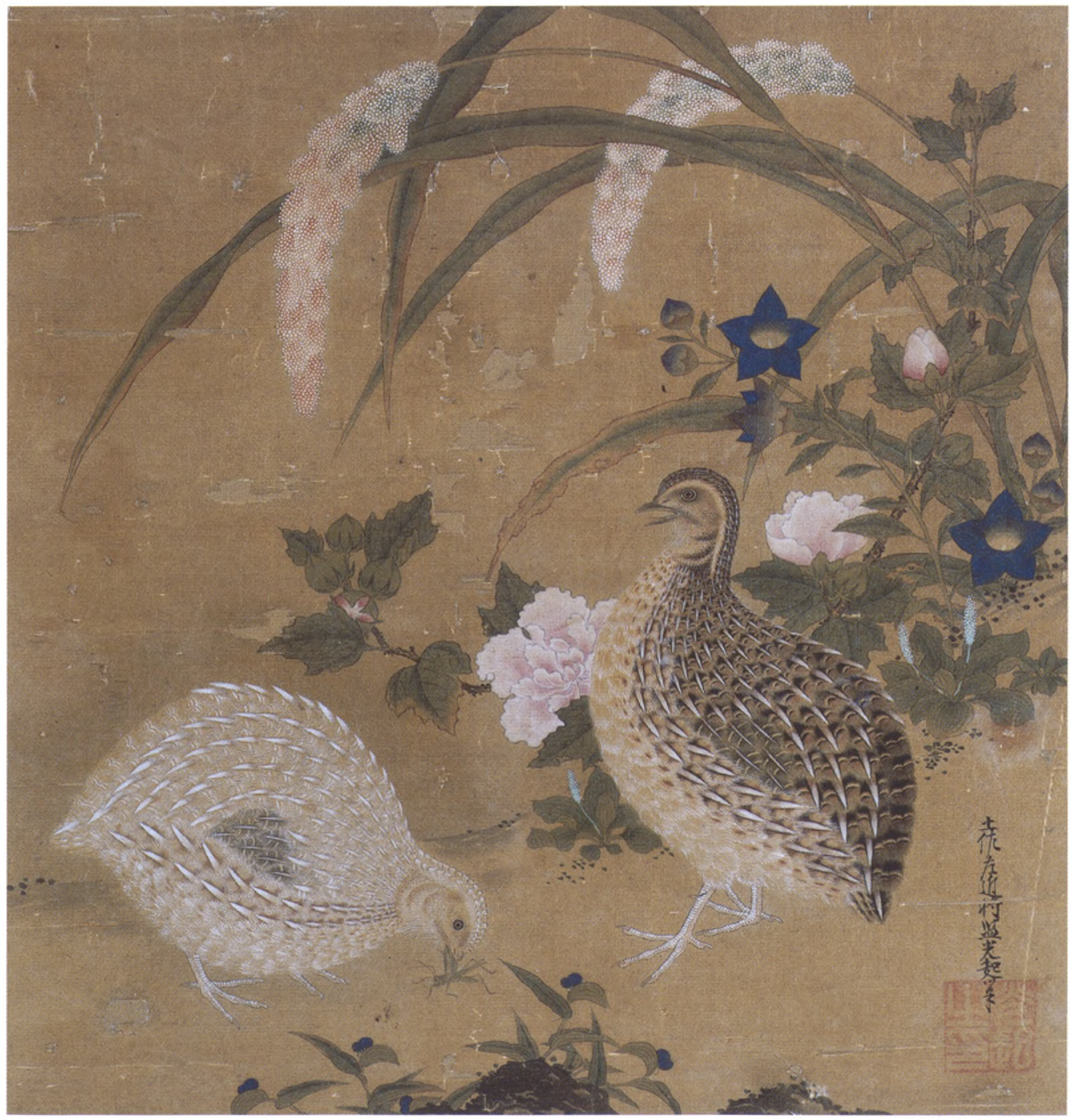




\title{
2. Kamuro en courtisane met hond
}

\author{
Ongesigneerd \\ Meireki- tot Kanbun-periode, ca. 1655-1673 \\ Hangrolschildering, inkt en kleur op papier \\ $52,0 \times 46,5 \mathrm{~cm}$. \\ AK-MAK-1 167
}

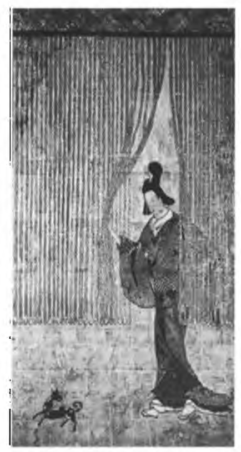

Twee staande figuren van vrouwen dragen kleding met kleurige motieven tegen een lichtblauwe achtergrond. De oudste van de twee, die een hond aan de lijn houdt, is een courtisane; het meisje met het haar tot op de schouders is een kamuro. ${ }^{6}$ Uit het feit dat ze beiden ongeschoeid zijn, kunnen we ons voorstellen dat het een scene is die zich binnenskamers in een bordeel afspeelt. De schildering heeft overeenkomsten met de zogenaamde Kanbunbijin afbeeldingen, zoals de ontspannen wijde kleding met de smalle obi, het karakteristieke ontwerp van de kleding en het haar in oude stijl. De datering zal niet ver af zitten van de Kanbun-periode (1661-1672), wellicht iets vroeger, zo rond het midden van de $17 \mathrm{e}$ eeuw. Afbeeldingen van Kanbun-bijin zijn de laatste stap in het ontstaan van de genre-schilderkunst in de vroege moderne tijd. Het zijn afbeeldingen van geïsoleerd weergegeven figuren (niet alleen vrouwen, maar ook acteurs en jeugdige dansers), gevat in een bijpassende montering. $\mathrm{Na}$ afbeeldingen van taferelen uit het al dan niet dagelijkse leven ging men zich nu beperken tot het thema van figuren van mooie mannen en vrouwen en hun kleding. Deze daarna nog lang voortgezette traditie krijgt hier voor het eerst haar vaste vorm.

Deze schildering is in een moderne montering gevat. De proporties zijn echter niet die van een doorsnee hangrolschildering: de schildering is nagenoeg vierkant. Er is rondom weinig marge en terwijl de interactie tussen de vrouw en haar hond een afgeronde indruk maakt, geeft de houding van de kamuro ietwat de indruk overbodig te zijn: alsof ze niet past in deze ruimte. Het kan zijn dat deze onevenwichtigheid en gebrek aan eenheid wordt veroorzaakt doordat het een uit een groter geheel gehaald stuk is, dat vervolgens apart is gemonteerd. Als we met dit in het achterhoofd het papier inspecteren, zien we dat zich boven en onder twee aangelijmde stroken papier bevinden en lijkt het waarschijnlijk dat het oorspronkelijk een deel van een kamerscherm is geweest. ${ }^{7}$ Het thema van een courtisane met een hond aan de lijn is een motief dat vaak uitgebeeld is op genre-schilderingen uit die tijd, zoals 'Kamuro met hond' uit het Chiba City-museum, dat waarschijnlijk model stond voor de boekillustratie in 'Kottoshu' (Verzameling van curiosa) van Santo Kyoden, of het kamerscherm 'Touwgordijn', waarop een courtisane met een hond vanachter een touwgordijn naar buiten komt (zie afbeelding). Dit laatste werk is een enkel rechterblad uit een van oorsprong tweeslags kamerscherm en men vermoedt dat het op de linkerhelft een afbeelding had van een mannelijke klant. Op dezelfde manier ging ook het Amsterdamse exemplaar waarschijnlijk oorspronkelijk vergezeld van een schildering van een man. Meer dan als een voorbeeld van een Kanbun-bijin schildering moeten we het dan ook beschouwen als een deel van een schildering van een bordeelscene, die vervolgens tot een op zich staand werk is gemaakt, om tegemoet te komen aan de fervente vraag naar afbeeldingen van mooie vrouwen. Dergelijke voorbeelden zijn er in grote getale aan te wijzen, met als vroegste voorbeeld de 'Bijin op veranda' uit het Tokyo National Museum. 





Late Heian-periode, ca. midden 12e eeuw

Hout

h. $89,5 \mathrm{~cm}$.

\section{AK-MAK-294}

Een beeld van Amida Nyorai gezeten in lotushouding met het linkerbeen boven, en de handen in jobon gesho ('bovenste graad, lage geboorte'). ${ }^{8}$ De schedeluitstulping op het hoofd is rond van vorm en vormt een eenheid met het hoofdhaar en de contour van het gezicht. De haargrens loopt kaarsrecht over het voorhoofd en de ronde krullen zijn klein gevormd. Het gezicht heeft boogvormige, serene wenkbrauwen en ietwat aangezette bovenste oogleden; de gevulde wangen geven het een welvarend uiterlijk. Het lichaam heeft zacht aflopende schouders, een weinig volumineuze borst en stabiel op de grond gelegde benen, dit alles omgeven door de soepele vouwen van een monniksgewaad. Het geheel geeft een indruk van eenheid, met het rustige ritme van het lijnenspel. Dit type is in de zogenaamde Jochostijl, uit de mid- tot late Heian-periode (794-1185), genoemd naar de beeldhouwer Jocho, die de Amida Nyorai in de feniks-hal van de Byodoin maakte. ${ }^{9}$ Vergeleken met de Amida Nyorai in de feniks-hal is dit exemplaar meer gestileerd en waarschijnlijk wat recenter.

Een niet erg in het oog vallend, maar voor deze periode ongebruikelijk kenmerk is het gestileerde monnikskleed, dat onder de rechterhand doorloopt, dan bij de buikpartij omgevouwen is en vervolgens over de rechterschouder is geslagen. Voorts is de rand van het kleed in het midden van de in lotushouding gehouden benen in een halfronde vorm gelegd. Dit is karakteristiek voor de Jocho-stijl en komt voor het eerst voor in de late Heian tijd, bijvoorbeeld bij de Amida Nyorai uit de tempels Sanzen'in en Joruruji in Kyoto, en is elders lokaal te zien bij boedda's uit de Kamakura-tijd (1185-1333), zoals de grote bronzen Amida Nyorai in de Kotokuji.

Dit uit verschillende houten blokken gemaakte beeld, met de in het hout gesneden ogen ${ }^{10}$ is nu van kaal hout, maar zal oorspronkelijk bedekt zijn geweest met goudfolie op een laag van lak.

Shimizu Masumi 


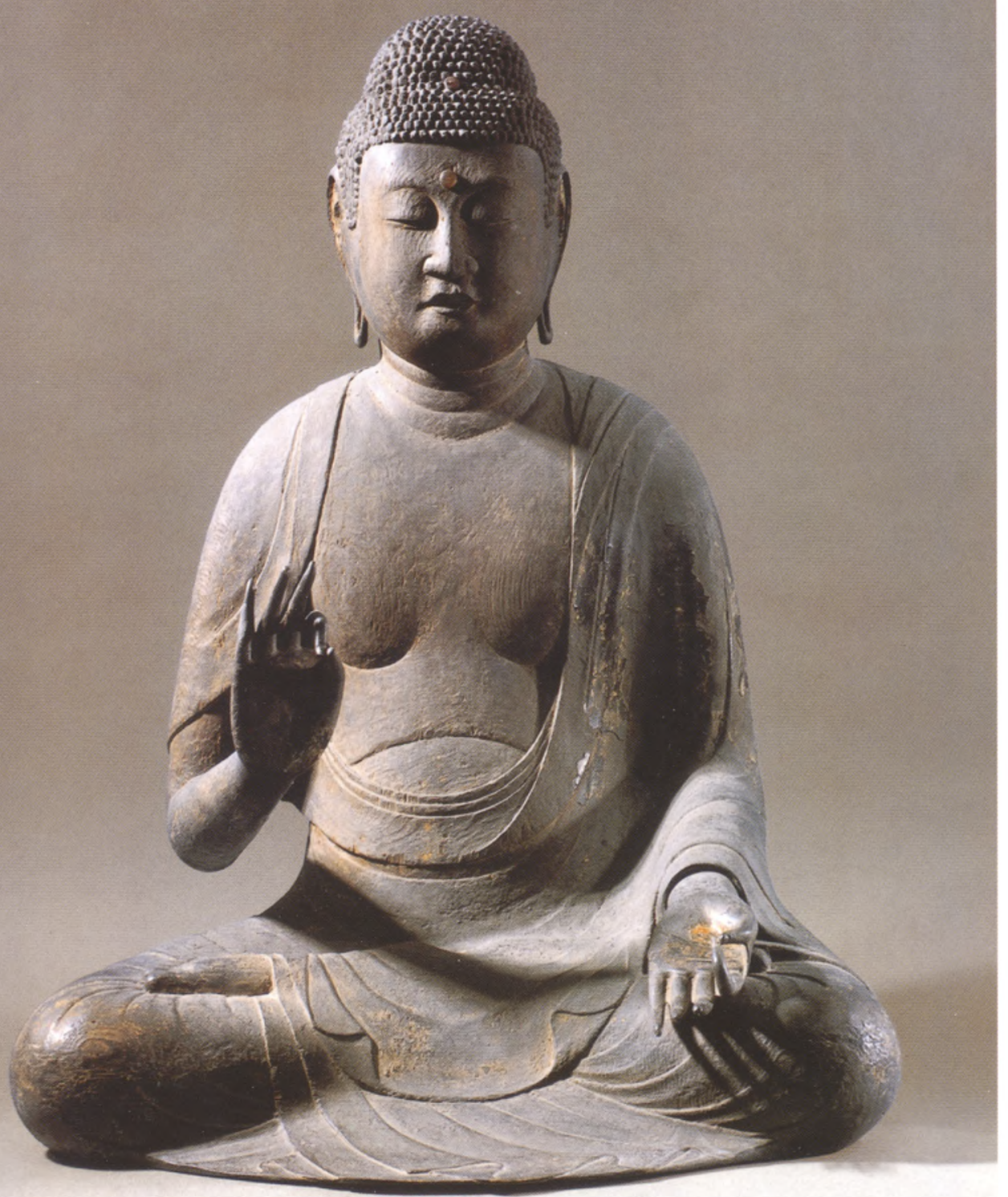


Late Kamakura-periode, tweede helft $13 \mathrm{e}$ - eerste helft $14 \mathrm{e}$ eeuw Hout

h. $106,5 \mathrm{~cm}$.

\section{AK·MAK-117}

Een staande figuur, gekleed in een monniksgewaad en met een geschoren hoofd, houdt beide armen gebogen voor zich. Gezien het feit dat beide handen verloren zijn gegaan en attributen ontbreken, is het weliswaar niet uitgesloten dat het een staande figuur van de bodhisattva Jizo is, maar aangezien er op het voorhoofd geen urna aangebracht is en het gezicht een menselijke, vriendelijke uitdrukking heeft, lijkt de toeschrijving van een monniksfiguur toch eerder juist te zijn. Het is waarschijnlijk een van de judai deshi, een groep van tien monniken van hoge rang, discipelen van Shaka (de Boeddha Shakyamuni), al is het lastig te zeggen welke van de tien het betreft, omdat er buitengewoon weinig voorbeelden van dit soort beelden zijn overgebleven. Echter, het jeugdige uiterlijk zou misschien passend kunnen zijn voor Ananda. ${ }^{11}$

Het monniksgewaad hangt ruim over de op de heup gedragen rok en het boord hangt recht over de rechterschouder naar beneden, een kenmerk dat doet denken aan de bronzen bodhisattva Jizo in de tempel Seidaiji in Fukui, uit het midden van de Kamakura-periode.

De milde uitdrukking op het gezicht is goed getroffen en er is geen onbalans in de verhouding tussen lichaam en hoofd, maar de bouw van het lichaam zelf (schouders, borst en buik etc.) is zwak en het eenvoudige gewaad is ook niet erg sterk. Het zal een werk uit de late $13 \mathrm{e}$ of de eerste helft van de $14 \mathrm{e}$ eeuw zijn.

Het beeld is uit meerdere blokken hout samengesteld, de ogen zijn in het hout gesneden en het beeld is oorspronkelijk beschilderd geweest.

Shimizu Masumi 


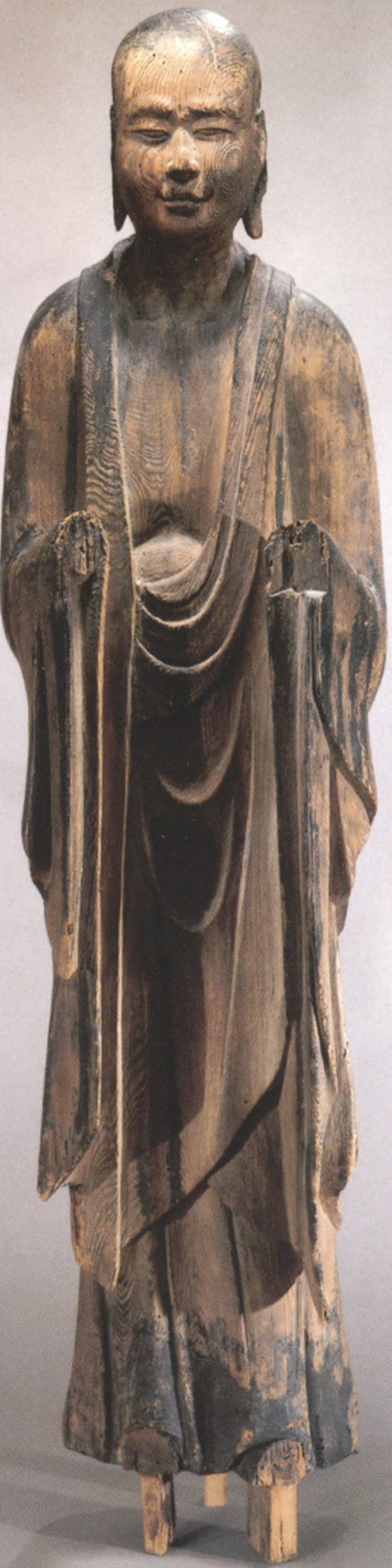


Late Heian- tot vroege Kamakura-periode,

laat $12 \mathrm{e}$ eeuw - vroeg $13 \mathrm{e}$ eeuw

Hout

h. $49,0 \mathrm{~cm}$.

AK-MAK-1 16

De staande bodhisattva Jizo houdt de rechterhand naar beneden en de linkerarm gebogen voor zich. Beide armen zijn vanaf de pols verloren gegaan, maar het beeld moet in de rechterhand een rinkelstaf hebben gehouden en in de linker een juweel.

Het hoofd is fors in verhouding tot het lichaam, maar doordat het geschoren gedeelte groot is ziet het zachtaardige gezicht met de urna op het voorhoofd er klein uit. Aan het lichaam valt verder de milde lijn op waarmee de schouders vormgegeven zijn. Er is een zeker realisme in de houding: de beeldhouwer heeft, naar aan te nemen met opzet, de schouder van de geheven linkerarm ietwat meer spanning meegegeven dan die van de rechterarm. Het beeld maakt op het eerste gezicht een niet erg bijzondere indruk, met het gewaad dat op de buik in een u-vorm valt en de wat brave draperie die bij de buik en van de beide benen naar de rand parallel is gestoken. Echter, als we goed kijken valt op dat er niets ongemakkelijks is in de manier waarop het hoofd op het lichaam staat en hoewel het terughoudend weergegeven is heeft de figuur ritme. Bij de vorm van de kleding valt op dat het kleed niet aan de rechterkant bij de borst is ingestopt, maar recht naar beneden hangt.

Het beeld is uit meerdere stukken hout samengesteld, de ogen zijn in het hout gesneden en het beeld is oorspronkelijk beschilderd geweest.

Shimizu Masumi 


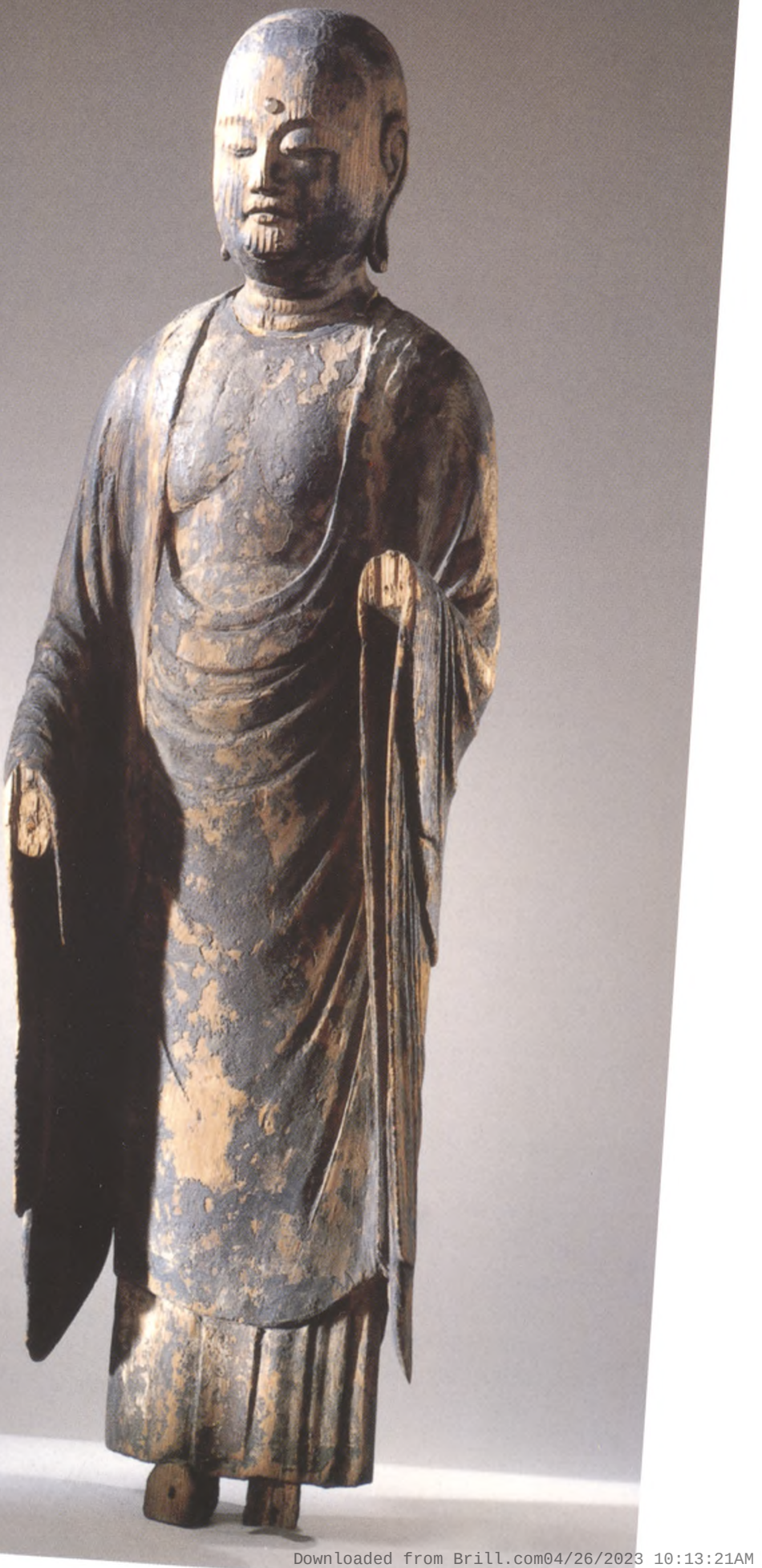


1. Hirayama Ikuo en Kobayashi Tadashi, red., Hizo nihon bijutsu taikan 12 delen, Tokyo, 1993.

2. Asiatic Dayflower, Commelina communis.

3. Het Japanse hof kent een systeem van rangen, die verdeeld zijn in 'lage' en 'hoge' graden.

4. Een uiteraard ceremoniële titel. De rang van luitenant was passend voor zijn hofrang van 'vijfde rang, lage graad'.

5. Hokkyo ('brug van de wet') en hogen ('oog van de wet') zijn twee eretitels die aan kunstenaars werden toegekend, naar analogie van het rangensysteem voor monniken.

6. Persoonlijke assistente van een courtisane, die al meelopend het vak leert.

7. De auteur duidt hier waarschijnlijk op het feit dat er voor de panelen van kamerschermen vellen papier van een vast formaat werden gebruikt, die met een kleine overlap onder elkaar werden geplakt.

8. Bij deze handhouding maken beide handen het gebaar van onderwijs. Dit heeft te maken met de rangen waarin stervelingen wedergeboren kunnen worden: heiligen, vromen en zondaren. Deze combinatie van gebaren hoort bij de hoogste klasse van de zondaren, de hoogste rang die voor mensen haalbaar is.

9. Tempel in Kyoto. Het beeld van de Amida Nyorai van Jocho (?-1057) is uit 1053.

10. De in het hout gesneden ogen waren met verf ingeschilderd; dit in tegenstelling tot de meer realistische latere techniek van ogen met ingelegd kristal, dat aan de achterkant van detaillering was voorzien.

11. Neef van Boeddha, bekend om zijn geheugen. Na de dood van zijn meester stelde hij sutra samen uit de leer van zijn meester. 